\title{
One too many diabetes: the combination of hyperglycaemic hyperosmolar state and central diabetes insipidus
}

\section{Snezana Burmazovic', Christoph Henzen², Lukas Brander1 and Luca Cioccari1,3}

1Departments of Intensive Care Medicine, IInternal Medicine and Endocrinology, Lucerne Cantonal Hospital, Lucerne, Switzerland, and ${ }^{3}$ Australian and New Zealand Intensive Care Research Centre, School of Public Health and Preventive Medicine, Monash University, Prahran, Australia

\section{Correspondence}

should be addressed

to L Cioccari

Email

luca.cioccari@monash.edu

\section{Summary}

The combination of hyperosmolar hyperglycaemic state and central diabetes insipidus is unusual and poses unique diagnostic and therapeutic challenges for clinicians. In a patient with diabetes mellitus presenting with polyuria and polydipsia, poor glycaemic control is usually the first aetiology that is considered, and achieving glycaemic control remains the first course of action. However, severe hypernatraemia, hyperglycaemia and discordance between urine-specific gravity and urine osmolality suggest concurrent symptomatic diabetes insipidus. We report a rare case of concurrent manifestation of hyperosmolar hyperglycaemic state and central diabetes insipidus in a patient with a history of craniopharyngioma.

\section{Learning points:}

- In patients with diabetes mellitus presenting with polyuria and polydipsia, poor glycaemic control is usually the first aetiology to be considered.

- However, a history of craniopharyngioma, severe hypernatraemia, hyperglycaemia and discordance between urine-specific gravity and osmolality provide evidence of concurrent diabetes insipidus.

- Therefore, if a patient with diabetes mellitus presents with severe hypernatraemia, hyperglycaemia, a low or low normal urinary-specific gravity and worsening polyuria despite correction of hyperglycaemia, concurrent diabetes insipidus should be sought.

\section{Background}

Hyperosmolar hyperglycaemic state (HHS) is the most serious acute hyperglycaemic emergency in patients with type 2 diabetes mellitus and carries a high mortality rate (1). Diagnostic criteria for HHS include a blood glucose level (BGL) $>33 \mathrm{mmol} / \mathrm{L}$ with no or only minimal ketosis, an effective serum osmolality $>320 \mathrm{mosmol} / \mathrm{kg}$, an arterial $\mathrm{pH}>7.3$ and a bicarbonate concentration greater than $18 \mathrm{mmol} / \mathrm{L}$. HHS is frequently associated with acute major illnesses, infections or inadequate insulin therapy. Moreover, HHS is commonly seen in older patients with type 2 diabetes who have compromised water intake due to underlying medical conditions.

Central diabetes insipidus (CDI) is characterized by decreased secretion of antidiuretic hormone (ADH or arginine vasopressin AVP) leading to variable degrees of polyuria. The most common causes are idiopathic diabetes insipidus, tumours, infiltrative or granulomatous diseases and trauma (2). Moreover, CDI can occur after neurosurgery, particularly after resection of a craniopharyngioma (3). 
We report a rare case of concurrent manifestation of HHS and CDI in a patient with a history of craniopharyngioma.

\section{Case presentation}

A twenty-two-year-old woman with a history of type 2 diabetes mellitus and panhypopituitarism after partial resection of a craniopharyngioma was admitted to our emergency department because of progressive leg pain, muscle weakness and polyuria. One week prior, she had suffered from a common cold. Her medication included pituitary hormone substitution with hydrocortisone, thyroxine, oestradiol/norgestrel, growth hormone

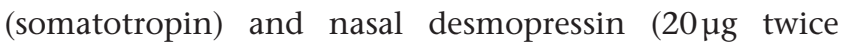
daily) as well as liraglutide for the treatment of diabetes. Her past medical history was notable for previous episodes of hyperosmolarity. This had been attributed to a decreased feeling of thirst and to malcompliance with the desmopressin regimen.

Her physical examination was unremarkable, including normal motor function and level of consciousness. The patient was afebrile (temperature: $36.6^{\circ} \mathrm{C}$ ), her bodyweight was $97 \mathrm{~kg}$ (BMI: $35 \mathrm{~kg} / \mathrm{m}^{2}$ ) and her blood pressure was 105/69 mmHg. Heart rate (79 bpm) and oxygen saturation were normal (98\% while breathing ambient air). Over the first $24 \mathrm{~h}$ after admission, her urine output was $3880 \mathrm{~mL}$.

\section{Investigation}

Initial laboratory analysis revealed severe hypernatraemia (serum sodium concentration $161 \mathrm{mmol} / \mathrm{L}$ ), moderate hypokalaemia $(3.2 \mathrm{mmol} / \mathrm{L})$, hyperglycaemia (BGL: $35.4 \mathrm{mmol} / \mathrm{L}$ ) and increased serum osmolality $(387 \mathrm{mosmol} / \mathrm{kg})$. The calculated free water deficit was $8.8 \mathrm{~L}$. Arterial blood gas analysis showed a mild hyperchloraemic metabolic acidosis with a normal anion gap (negative strong ion difference of $-9 \mathrm{mmol} / \mathrm{L}$ ). The complete blood test results on admission are presented in Table 1.

\section{Treatment}

The initial diagnosis of HHS was made in the emergency department, and the patient was treated with intravenous volume repletion consisting of $1000 \mathrm{~mL}$ of $5 \%$ dextrose in water (D5W), $1000 \mathrm{~mL}$ of $0.45 \%$ saline and $3000 \mathrm{~mL}$ of a balanced crystalloid solution (Ringerfundin, B. Braun, Germany) during the following $10 \mathrm{~h}$. In addition, she was
Table 1 Blood test results on admission to the emergency department.

\begin{tabular}{|c|c|c|}
\hline Variable & Result & Reference range \\
\hline Haemoglobin & 145 & $115-148 \mathrm{~g} / \mathrm{L}$ \\
\hline Leukocytes & 4.2 & $2.6-7.8 \times 109 / \mathrm{L}$ \\
\hline Platelets & 159 & $130-330 \times 10 \% / L$ \\
\hline Haematocrit & 0.43 & $0.34-0.43$ \\
\hline INR & 1.0 & $1.0-1.1$ \\
\hline Sodium & $161^{*}$ & $136-145 \mathrm{mmol} / \mathrm{L}$ \\
\hline Potassium & $3.2^{*}$ & $3.4-4.5 \mathrm{mmol} / \mathrm{L}$ \\
\hline Chloride & $132 *$ & $98-106 \mathrm{mmol} / \mathrm{L}$ \\
\hline Calcium & $2.66^{*}$ & $2.15-2.5 \mathrm{mmol} / \mathrm{L}$ \\
\hline Osmolality serum & $387^{*}$ & $280-300 \mathrm{mosmol} / \mathrm{kg}$ \\
\hline Urea nitrogen & 6.2 & $1.7-8.3 \mathrm{mmol} / \mathrm{L}$ \\
\hline Creatinine & 80 & $45-84 \mu \mathrm{mol} / \mathrm{L}$ \\
\hline Glucose & $35.4^{*}$ & $3.8-6.4 \mathrm{mmol} / \mathrm{L}$ \\
\hline ALT & $77^{*}$ & $<35 \mathrm{U} / \mathrm{L}$ \\
\hline $\mathrm{LDH}$ & 393 & $240-480 \mathrm{U} / \mathrm{L}$ \\
\hline Alkaline phosphatase & $140^{*}$ & 35-105 U/L \\
\hline Creatine kinase & 70 & $<170 \mathrm{U} / \mathrm{L}$ \\
\hline CRP & $6^{*}$ & $<5 \mathrm{mg} / \mathrm{L}$ \\
\hline $\mathrm{HbA1c}$ & $8.7^{*}$ & $<6 \%$ \\
\hline \multicolumn{3}{|c|}{ Venous blood gas analysis } \\
\hline $\mathrm{pH}$ & $7.269^{*}$ & $7.35-7.45$ \\
\hline $\mathrm{pCO} 2$ & $7.35^{*}$ & $4.27-6.0 \mathrm{kPa}$ \\
\hline pO2 & 4.68 & $11.07-14.4 \mathrm{kPa}$ \\
\hline Bicarbonate & 25.3 & $22-26 \mathrm{mmol} / \mathrm{L}$ \\
\hline Lactate & 1.3 & $0.5-1.6 \mathrm{mmol} / \mathrm{L}$ \\
\hline
\end{tabular}

*Denotes abnormal values.

ALT, alanine aminotransferase; INR, international normalized ratio; LDH, lactate dehydrogenase.

given intravenous (IV) hydrocortisone (200 mg/day in four divided doses), oral and IV potassium supplementation and repeated boluses of subcutaneous insulin (in total $14 \mathrm{IU}$ of regular insulin over $10 \mathrm{~h}$ ). This rather cautious insulin regime was chosen because of the hypokalaemia, in accordance with current recommendations. Her usual dose of nasal desmopressin was continued. However, although the BGL decreased from 35.4 to $27.0 \mathrm{mmol} / \mathrm{L}$ after $10 \mathrm{~h}$, serum sodium increased to a peak level of $169 \mathrm{mmol} / \mathrm{L}$, and polyuria persisted. The patient was then transferred to the intensive care unit (ICU) for further evaluation and treatment.

Upon arrival in the ICU, the patient's BGL was $26.0 \mathrm{mmol} / \mathrm{L}$ and the serum sodium level was $165 \mathrm{mmol} / \mathrm{L}$. After further fluid replacement with $0.45 \%$ saline and D5W, and after increasing the IV insulin infusion up to $14 \mathrm{IU}$ per hour, the BGL decreased gradually to $14.5 \mathrm{mmol} / \mathrm{L}$. However, hypernatraemia as well as polyuria persisted. Urine osmolality was moderately high at $773 \mathrm{mosmol} / \mathrm{kg}$, while urine-specific gravity was low at 1.011. Considering the patient's history, concurrent manifest diabetes insipidus was suspected and an additional dose of $2 \mu \mathrm{g}$ 
IV desmopressin was administered. Thereafter, serum sodium levels gradually normalized (Fig. 1). The urine output decreased $650 \mathrm{~mL} / 24 \mathrm{~h}$ and remained between 1400 and $1600 \mathrm{~mL} / 24 \mathrm{~h}$ after IV desmopressin. Nasal desmopressin was continued and IV hydrocortisone was gradually tapered to the usual maintenance dose.

\section{Outcome and follow-up}

Over the next 2 days, BGL, electrolytes and acid-base status returned to normal and the clinical symptoms of muscle weakness and leg pain disappeared. The patient was discharged from the hospital on day 7 and recovered fully.

\section{Discussion}

The combination of hyperglycaemic hyperosmolar state and CDI is unusual and comprises unique diagnostic and therapeutic challenges for the treating physician. The coexistence of diabetes mellitus and diabetes insipidus was first described by Don Wolfram (4) in 1938 and represents the hallmark of Wolfram syndrome or DIDMOAD (diabetes insipidus, diabetes mellitus, optic atrophy and deafness). Coexistence of CDI and diabetes mellitus has also been described in the context of pituitary metastases (5), hypoxic brain injury (6) and idiopathic CDI (7). Patients with craniopharyngioma are at increased risk for obesity, mainly due to infiltration of the tumour into the hypothalamus, resulting in an impaired sense of satiety ultimately leading to insulin resistance and type 2 diabetes. Consequently, the risk for diabetes mellitus

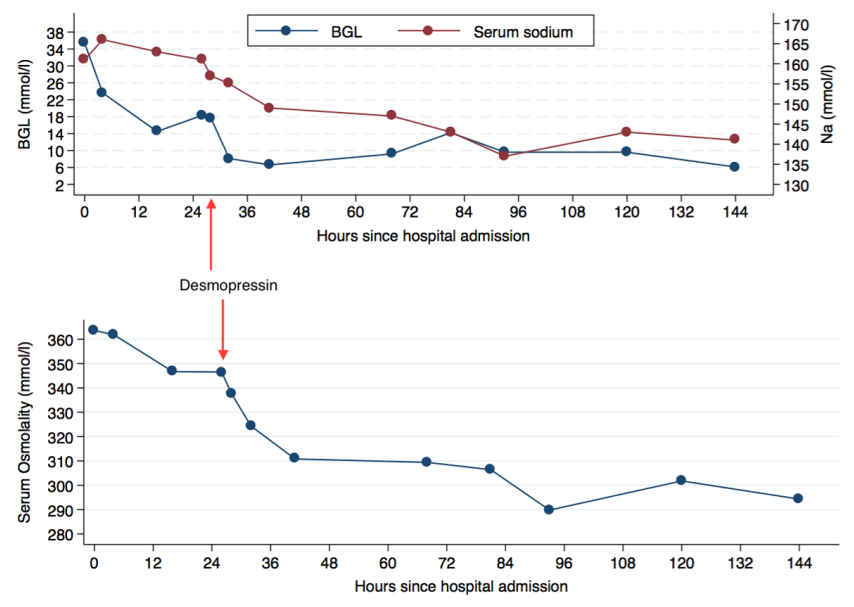

\section{Figure 1}

Blood glucose, serum sodium levels (upper section) and calculated serum osmolality (lower section) from admission to the emergency department until hospital discharge. BGL, blood glucose level; $\mathrm{Na}$, serum sodium. is increased $(8,9)$. Therefore, the combination of these two diabetes forms in this specific population is not unexpected, but remains a clinical challenge.

In our patient, a possible trigger for the HHS may have been the upper airway infection. The inflammation of the nasal mucous membranes may have resulted in malabsorption of desmopressin, leading to polyuria and dehydration, which per se aggravated the hyperglycaemia. An impaired sensation of thirst after partial resection of the craniopharyngioma and the polyuria-induced tubular resistance to vasopressin might also have played a role. However, the prompt response to parenteral administration of vasopressin favours the first hypothesis.

Surprisingly, our patient experienced only mild neurological symptoms of hyperosmolarity, without impairment of neurocognitive function. A possible explanation is that she may have adapted to chronic hypernatraemia as a result of under-dosing of desmopressin, secondary to the documented treatment malcompliance.

In summary, if a patient with diabetes mellitus presents with polyuria and polydipsia, poor glycaemic control is usually the first aetiology to be considered, and achieving glycaemic control remains the first course of action. Discordance between urine-specific gravity and osmolality may suggest concurrent diabetes insipidus (7), but this phenomenon can also occur in patients with nephrotic syndrome, after administration of IV radiocontrast material or after mannitol (10). However, simultaneous elevation of serum sodium and BGL in a patient with a history of craniopharyngioma, points towards the diagnosis of concurrent CDI.

\section{Declaration of interest}

The authors declare that there is no conflict of interest that could be perceived as prejudicing the impartiality of the research reported.

\section{Funding}

This research did not receive any specific grant from any funding agency in the public, commercial or not-for-profit sector.

\section{Patient consent}

Written informed consent was obtained from the patient for publication of this case report.

Author contribution statement

S Burmazovic collected the data, searched the literature and drafted the manuscript under the supervision of $L$ Cioccari. $C$ Henzen revised the 
manuscript for important intellectual content. L Brander was the consultant intensivist responsible for the patient and revised the manuscript.

\section{References}

1 Pasquel FJ \& Umpierrez GE. Hyperosmolar hyperglycemic state: a historic review of the clinical presentation, diagnosis, and treatment. Diabetes Care 201437 3124-3131. (https://doi.org/10.2337/dc14 0984)

2 Maghnie M, Cosi G, Genovese E, Manca-Bitti ML, Cohen A, Zecca S, Tinelli C, Gallucci M, Bernasconi S, Boscherini B, et al. Central diabetes insipidus in children and young adults. New England Journal of Medicine 2000343 998-1007. (https://doi.org/10.1056/ NEJM200010053431403)

3 Crowley RK, Hamnvik OP, O'Sullivan EP, Behan LA, Smith D, Agha A \& Thompson CJ. Morbidity and mortality in patients with craniopharyngioma after surgery. Clinical Endocrinology $2010 \mathbf{7 3}$ 516-521. (https://doi.org/10.1111/j.1365-2265.2010.03838.x)

4 Wolfram DJ \& Wagener HP. Diabetes mellitus and simple optic atrophy among siblings: report of four cases. Mayo Clinic Proceedings $19381715-718$.

5 Dogansen SC, Sertcelik G, Urfali FE \& Cirpan I. Diabetıc hyperosmolar nonketotic coma induced by central diabetes insipidus. Journal of Diabetes, Metabolic Disorders and Control 20152 00054. (https://doi.org/10.15406/jdmdc.2015.02.00054)

6 Masood M, Kumar S, Asghar A \& Jabbar A. An unusual case of central diabetes insipidus \& hyperglycemic hyperosmolar state following cardiorespiratory arrest. BMC Research Notes 20136 325. (https://doi. org/10.1186/1756-0500-6-325)

7 Akarsu E, Buyukhatipoglu H, Aktaran S \& Geyik R. The value of urine specific gravity in detecting diabetes insipidus in a patient with uncontrolled diabetes mellitus: urine specific gravity in differential diagnosis. Journal of General Internal Medicine 200621 C1-C2. (https://doi.org/10.1111/j.1525-1497.2006.00454.x)

8 Andereggen L, Hess B, Andres R, El-Koussy M, Mariani L, Raabe A, Seiler RW \& Christ E. A ten-year follow-up study of treatment outcome of craniopharyngiomas. Swiss Medical Weekly 2018148 w14521. (https://doi.org/10.4414/smw.2018.14521)

9 Wijnen M, Olsson DS, van den Heuvel-Eibrink MM,

Hammarstrand C, Janssen J, van der Lely AJ, Johannsson G \& Neggers S. Excess morbidity and mortality in patients with craniopharyngioma: a hospital-based retrospective cohort study. European Journal of Endocrinology 2018178 95-104. (https://doi. org/10.1530/EJE-17-0707)

10 Chadha V, Garg U \& Alon US. Measurement of urinary concentration: a critical appraisal of methodologies. Pediatric Nephrology 200116 374-382. (https://doi.org/10.1007/ s004670000551

Received in final form 12 March 2018

Accepted 23 March 2018 